\title{
Slope Stability in High Stress and Hard Rock Conditions
}

\author{
T.R. Stacey University of the Witwatersrand, South Africa
}

\begin{abstract}
Open pit mines are being planned to greater depths that will certainly involve high stress and hard rock conditions. These conditions are not satisfactorily accounted for by conventional stability analysis approaches that are based on the common mechanisms of failure involving planar, wedge and circular shear surface, and toppling. Failure mechanisms in high, hard rock slopes are much more complex than this. Progressive failure in hard rock slopes involves initiation and progression of failure along existing weakness planes, and initiation and progression of failure in intact rock.

Mechanisms of slope failure behaviour, and the implications for slope stability analysis and slope design, are considered in this paper. It is concluded that what is required for robust stability evaluation and design is much better understanding of the rock mass, and methods of analysis that can model the rock mass and take into account variability in all of the geotechnical parameters. Better site investigations and modern methods of slope monitoring should supply considerable information regarding the understanding of the three dimensional rock mass. Owing to geotechnical variability, data must be expressed in the form of statistical distributions, and methods of stability analysis must therefore be probabilistic rather than deterministic. The output from such analyses will not be a single evaluation, but a distribution of evaluations that will form the basis for a decision on the acceptability of risk of failure. Although the methods required for such analyses are already available in theory, they cannot yet be practically implemented because of lack of computing power. In particular, the requirement that analyses are probabilistic and three dimensional places enormous demands on computing capacity.
\end{abstract}

\section{Introduction}

The environment in which rock slopes are excavated has traditionally been considered to be a near surface, low stress environment, in which stability is controlled to a significant extent by major geological structures such as faults (Hoek et al., 2000a; Hoek et al., 2000b). These geological structures represent a factor over which the engineer designing the slope or evaluating its stability has no control. Their presence simply has to be accepted and taken into account in stability evaluation and slope design. The 'surfaces' of failure 'defined' by these larger geological structures, and the equilibrium of the mass of rock above surface, are the focus of the great majority of rock slope stability analyses carried out today. These analyses ignore the stresses that are present in the slope and also ignore the progressive deformations that may be taking place within the rock mass. They also neglect the smaller scale geological structures such as joints that may have an influence on slope stability, commonly on a local scale. The influences of these 'minor' structures on a larger scale are not well understood, and many engineers usually associate their influence with the 'rock mass strength'. Hoek et al. (2000a) indicated that the determination of the rock mass strength is a major deficiency in rock slope design practice. What about the influence of stress? In a review of progress that has been made in the rock slope stability field, carried out ten years ago (Stacey, 1996), the following quote from Merrill and Wisecarver (1967) was included, "In summary, the problem of the design of stable slopes, or foundations, in rock reduces to the ability of the rock to withstand stress. At present we know very little about the ability of a large mass of rock to withstand stress, and know even less about the stresses". Based on the deficiency in the ability to determine the rock mass strength (Hoek et al., 2000a), it may be concluded that this statement is still valid. The deficiency in the understanding is very serious, since the excavation of very deep pits to depths exceeding $1000 \mathrm{~m}$ are being planned (Sjoberg, 2000; Hoek et al., 2000a; Hoek et al., 2000b). At these depths, stresses will be high and therefore may be a significant factor in slope stability analysis and slope design. However, is it only at these depths that stresses become important? There is considerable evidence to show that stress is already playing an important role in the behaviour of slopes with low heights that are well within the range of slope heights in the existing experienced base. From this it would appear that the above statement from Merrill and Wisecarver (1967) continues to have validity. 
In the past ten years there have been significant advances in the capabilities of analysing and monitoring the behaviour of rock slopes. Advanced computer hardware and sophisticated numerical stress and deformation analysis codes, including continuum (finite element, boundary element and finite difference) and discontinuum (discrete and distinct element) codes, as well as hybrids of these, are commercially available for analysing rock mass behaviour. In addition to the improved means of slope analysis, there have been major advances in the ability to monitor slope behaviour through the development of slope radar, laser monitoring, automated survey, and satellite radar. Slope behaviour can now be observed and recorded in real time. Further, seismic monitoring of slopes provides a means of 'volumetric' monitoring compared with the surface monitoring delivered by the above methods. The availability of these monitoring and analysis techniques should provide a huge boost to the future ability to understand and model rock slope behaviour from the initiation of failure through to the ultimate collapse of the slope.

In this paper, mechanisms of slope behaviour in hard rock conditions are discussed prior to addressing the issues of slope design and prediction of slope behaviour.

\section{Mechanisms of slope failure behaviour}

The four common or 'standard' mechanisms of slope failure that have been used as the basis for slope stability analysis and slope design for many years are plane failure, wedge failure, shear failure on a circular or curved failure surface, and toppling failure (Wyllie and Mah, 2004). The methods of analysis based on these mechanisms of failure can generally be said to have served the geotechnical engineer well. It is probably fair to say that the engineers have gained a good feel for the usage of the methods of analysis and therefore are tending to use the analyses in an empirical or manipulative way rather than in an absolute way. For example, in limit equilibrium analysis, which depends on the evaluation of rigid body stability above a defined failure surface, the engineer may specify bands within which the failure surface must be located. The engineer therefore imposes on the analysis his knowledge, experience, or simply his intuition with regard to, the expected behaviour of that slope. Similarly, in stress analysis type stability analyses, the rock mass properties used as input parameters may depend on the experience or 'feeling' of the engineer. These design interventions are engineering judgement based, and only have validity as long as the slopes continue to behave in the way that has been experienced before. However, there is increasing evidence of slope behaviours that do not correspond with the common mechanisms, particularly when stress appears to be a factor. Moreover, with slope designs being planned for slope heights much greater than have been experienced before (Sjoberg, 2000) and therefore in higher stress environments, the validity of the common mechanisms of behaviour in these new, much more challenging environments is perhaps questionable.

A question to pose at this stage is, 'What is failure?' Is it slope collapse? Is it significant slope deformation that has involved failure of some kind? An example of unexpected behaviour of a very low height slope is shown in Figures 1 to 3. The slope involved is that in a small dimension stone quarry in high quality granite. The setting is shown in Figure 1 and the extent of the quarry is shown in Figure 2. The cut faces are a few metres in height. The granite is very high quality rock whose strength is unlikely to be less than $200 \mathrm{MPa}$. The stresses in the rock are unknown, but, taking into account the near surface location and the shallowness of the quarry, are unlikely to exceed say $10 \mathrm{MPa}$. Even if higher than these magnitudes, the stress would be unlikely to be anywhere near the strength of the rock. 


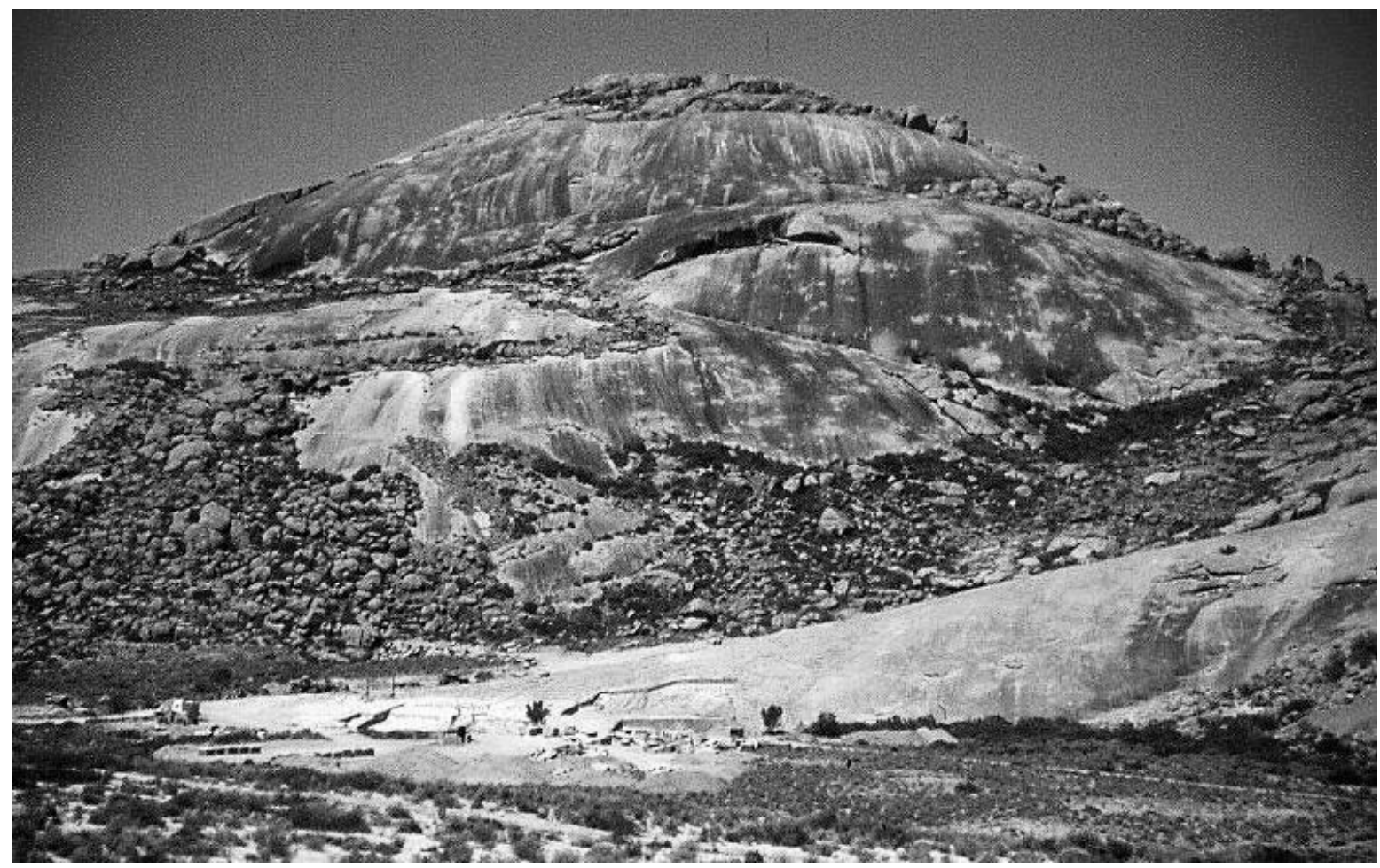

Figure 1 Setting of dimension stone granite quarry

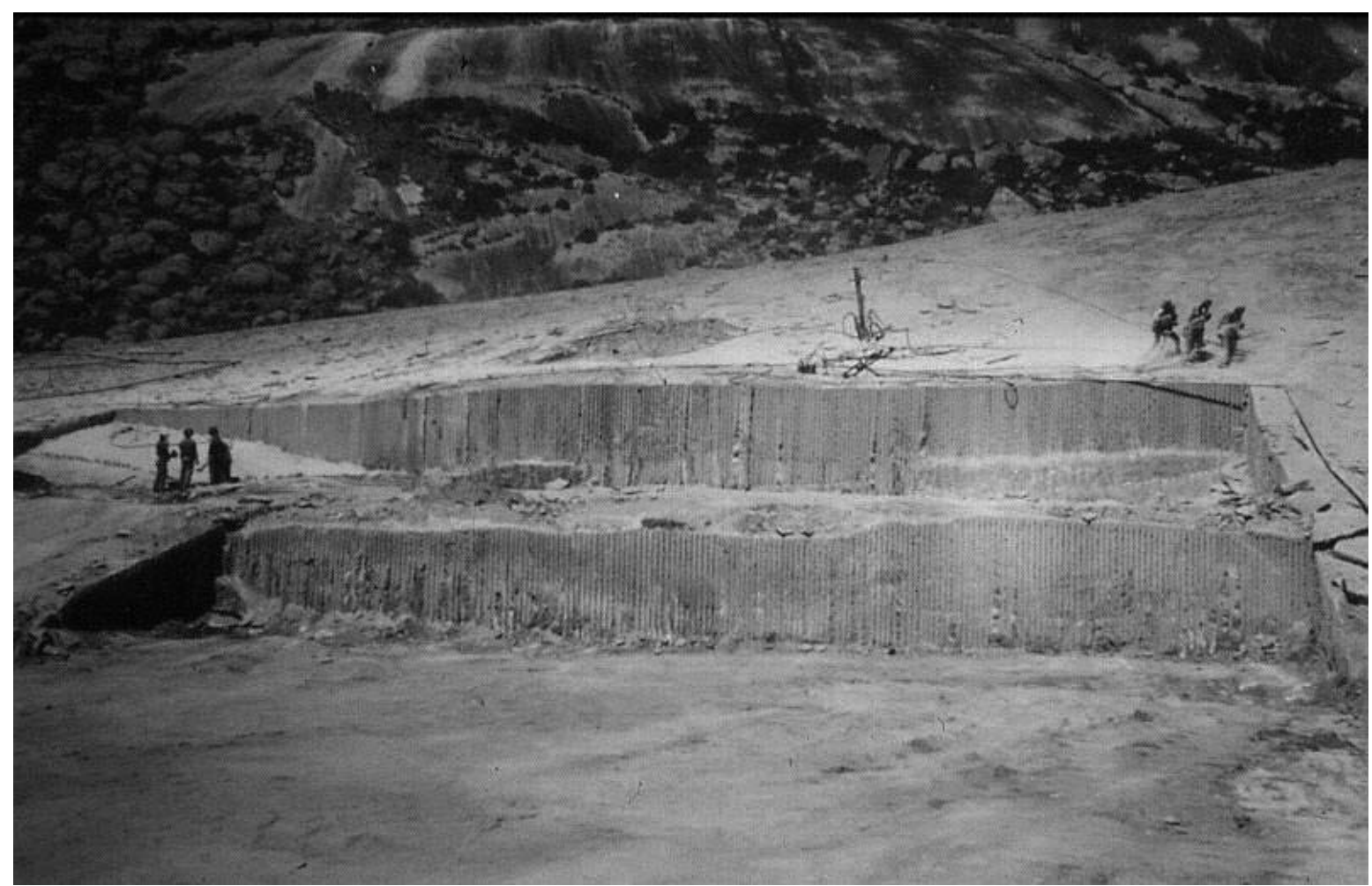

\section{Figure 2 Extent of quarry}

After excavation, fractures developed, often with considerable violence, sub-parallel to the surface, as shown in Figure 3. Minor offsets of the holes can be seen, and this behaviour was more pronounced at other locations. Vertical fractures developed subsequently, parallel to the cut face of the quarry, as shown in the right hand photograph in Figure 3. 

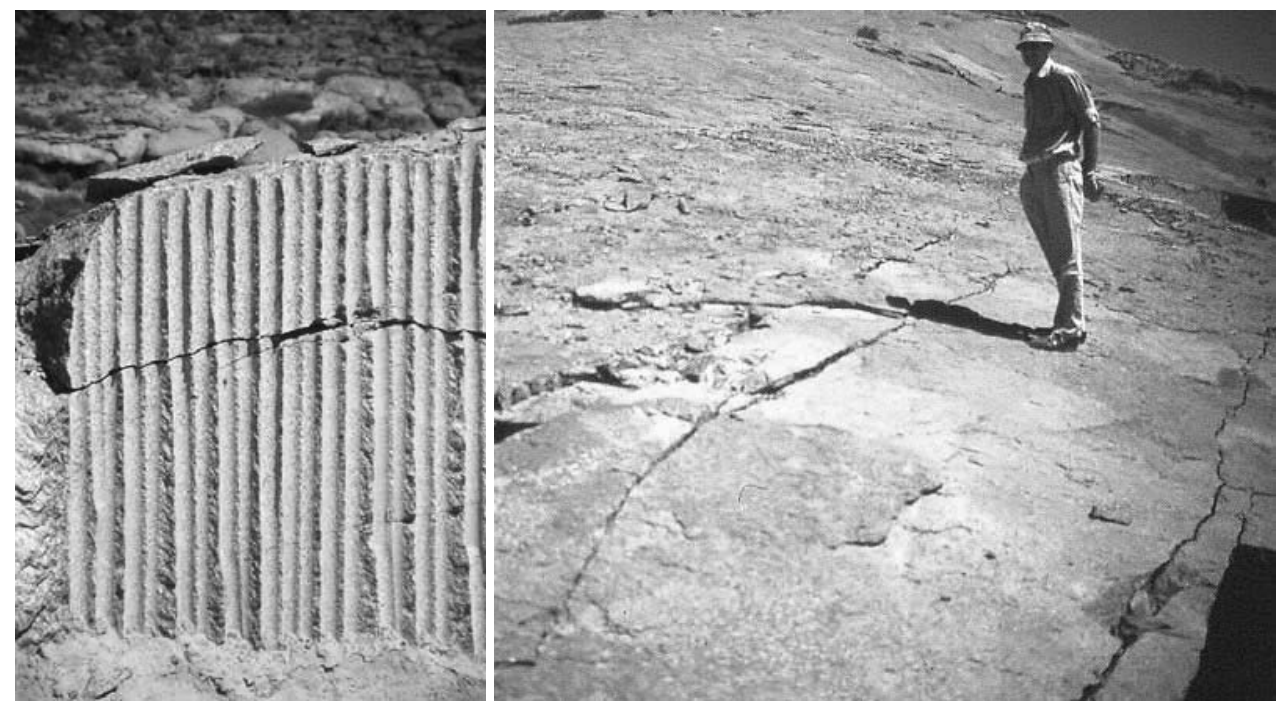

Figure 3 Stress-induced fractures sub-parallel to the surface and to the quarry face

It is clear that the slope has remained stable, but that some failure has certainly taken place. The occurrence of the fracturing is very detrimental to the mining operation, namely to produce large unfractured blocks of granite. There may be some similarity between this behaviour and that of an open pit slope described briefly by Stacey et al. (2003a), in which the 'failure' of a slope involved upwards and backwards displacements of a bench crest.

A second example which might question the definition of failure is the road cutting shown in Figure 4. In this case, a slope failure developed and there was mass movement resulting in an extensive tension crack maybe a metre wide and $10 \mathrm{~m}$ deep, indicated in Figure 4. After this movement, the slope stabilised and has been so for the last ten years. Was this a slope failure? Clearly, at some stage the 'factor of safety' dropped below unity.

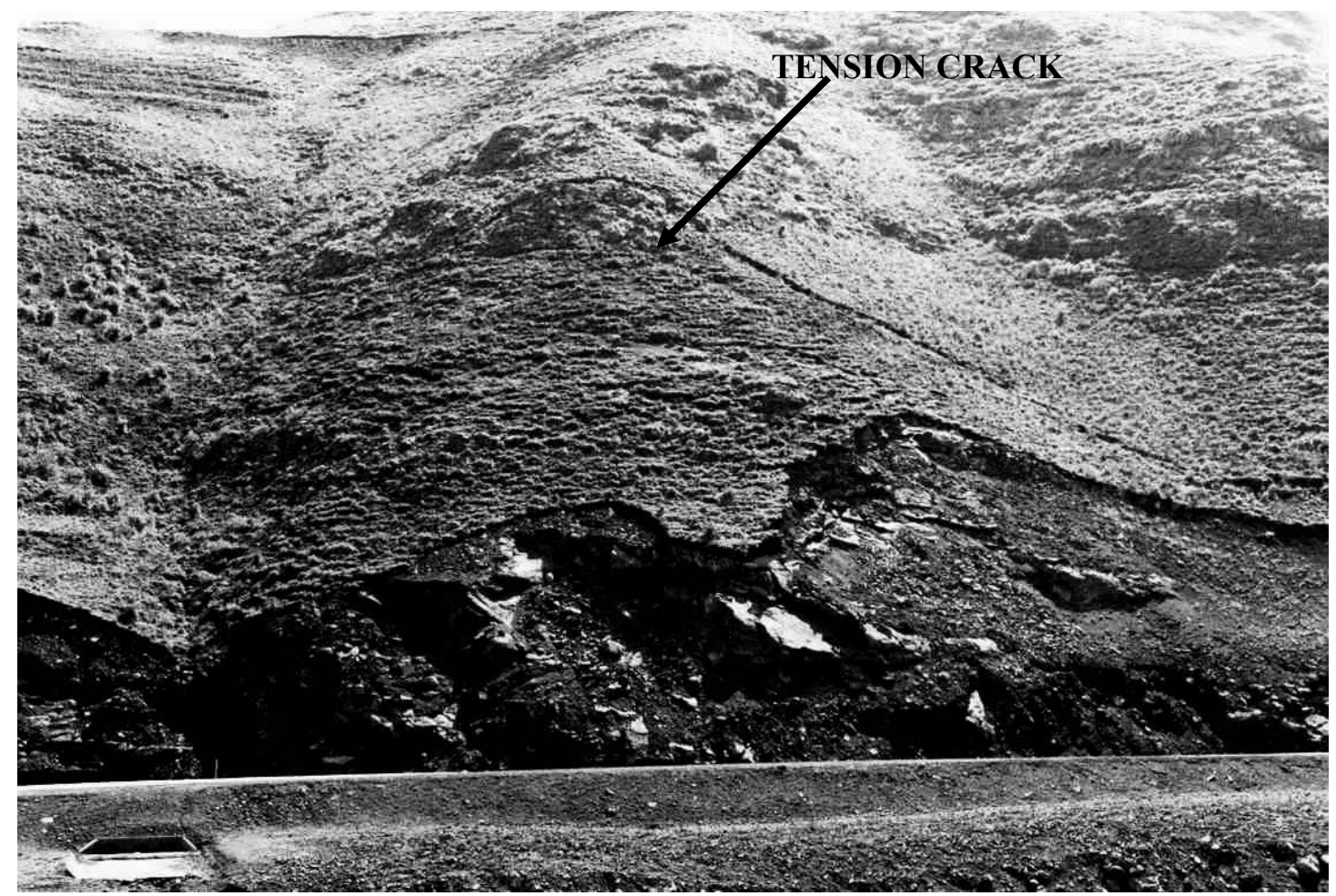

Figure 4 Road cutting with extensive tension crack 
Several recent publications have indicated unexpected slope failures and it is probable that there are many more such cases that are not in the public domain. Dight (2006) has described three cases of unexpected slope failures. In the first case, the failure was $200 \mathrm{~m}$ horizontally, $80 \mathrm{~m}$ vertically and $10 \mathrm{~m}$ in depth. Audible cracking had been experienced over several months preceding the failure. These 'noises' are indicative of the occurrence of failure through intact rock and the development of new fracture surfaces. In the second case, also involving failure over about an $80 \mathrm{~m}$ height, the interpretation was buckling in a schist zone with subsequent flexural failure and sliding on the shallow dipping plane formed. Again this represented a stress-induced failure. In the third case, both failure in a compression zone and toppling failure in a 'tensile' zone, were interpreted from the Kirsch stress equations. In this case, extensometers showed that deformations were occurring $100 \mathrm{~m}$ behind the slope face.

Simmons and Simpson (2006) studied numerous slope failures in a coal mining environment. They concluded that failure was relatively rapid, often without warning. They found that, in apparently the same rock and structural environment, it was not possible to determine why a failure occurred in one location and not in another. Back analyses of failures were not successful in matching rock mass shear strength parameters to failure conditions. Their experiences of failures in these rocks contradicted what might be considered as conventional geotechnical practice: discontinuity data collected has not been particularly helpful in predicting failures; conventional limit equilibrium analyses cannot be used to obtain satisfactory factors of safety or probabilities of failure; satisfactory rock mass shear strengths cannot be obtained from the usual rock strength tests and measurement of discontinuity surfaces; and, the extent of the failure zone cannot be predicted from conventional observations of rock mass conditions. They consider that, owing to stress, excavation leads to extensional deformation (reduction of confinement) and sudden failure occurs when a critical stress level has developed that can no longer be sustained by the rock mass.

Lucas (2006) described a 'sudden and catastrophic' failure in an open cut coal mine. It was apparent that shearing took place through intact rock at the toe of the slope. No discontinuities were present in this zone that could have provided such a failure surface. Limit equilibrium stability analyses appeared to be inappropriate, which supports the opinions of Simmons and Simpson (2006). A discontinuum numerical model was successfully used to explain the failure. Such explanations of failures can be very useful, and can be a basis for design of other slopes in the same environment.

The occurrence of seismicity in rocks is an indication of the development of new fractures due to stress. Seismic monitoring at Navachab Mine (Lynch et al., 2005; Stacey et al., 2004) has detected the occurrence of events some distance behind the slope face. Audible events were also experienced in the pit. A shallow slope failure occurred in the region where the deeper seismic events were subsequently recorded. At this time the depth of the pit was only about $120 \mathrm{~m}$. Monitoring of microseismicity in slopes could provide advance warning of slope failure development and information on new mechanisms of failure (Sweby, 2004). Such microseismicity may be associated with extension in the rock mass (Stacey et al., 2003a; Stacey et al., 2003b).

The pit slope failure described by Naismith and Wessels (2005) is interesting in that the extent of failure was much larger than had been expected from visual observations and conventional prism displacement monitoring. Initial localised failures in the area had occurred up to two years earlier. Shortly prior to the ultimate collapse a loud 'bang' was heard which apparently corresponded with the formation of the tension crack or scarp at the back of the failure (Naismith, pers. comm., 2007). This failure was managed using radar monitoring, with which equipment it was possible to detect and monitor the full extent of the failure. The complex nature of the deformations of the failing mass is also evident from the radar data, with different locations moving at different rates at different times. This complex type of behaviour was also noted by Mercer (2006) in failures monitored using prisms and survey techniques.

Any excavation process in rock involves 'unloading' or stress relief of the rock subjected to the in situ stresses, and the resulting redistribution of stresses. The excavation of underground openings such as tunnels and caverns usually involves relatively small exposed surface areas and volumes, and there is continued three dimensional confinement of the rock mass close to the excavation. Mining of open pits, in contrast, exposes very extensive surfaces, and the rock adjacent to the pit walls therefore becomes unconfined in the direction normal to the slope face over large areas. The rock mass in the zones of low confinement adjacent to the slope face will be subjected to varying stress changes as mining progresses and to the effects of the 
excavation process (usually blasting). Shear stresses acting on discontinuities will change, new fractures may be created in previously intact rock and these may interact with the natural discontinuities. Time is also a very important factor with regard to the development of failure and new fractures in the rock. When the geometry in a mine changes slowly and the slope toe is exposed to stress concentrations for a long period of time, new fractures have time to develop, creating new surfaces of movement, and existing planes may weaken further. This zone in the rock mass will then become a weakened zone that may influence slope behaviour when the pit is deepened at a later stage. This behaviour might be quite different from the behaviour that might occur if the geometry was changing rapidly in the same rock mass.

An example of a slope failure due to changed stress conditions is at Palabora Mine (Moss et al., 2006), where underground caving initiated failure of open pit slopes that could be said to have been completely stable during their mining to a depth of just over $800 \mathrm{~m}$. The caving caused a change in the stress environment, which resulted in conditions that allowed a major failure to develop.

All of these cases are well within the experience range of slope heights (Palabora is near the upper limit). From the observations and interpretations it may be concluded that slope behaviour is possibly always much more complex than the common slope failure mechanisms may indicate, and that the validity of methods of analysis based on these common mechanisms may often be in doubt.

The examples of slope behaviour described briefly above illustrate quite clearly that slopes do not commonly behave in a 'standard' way. The simple model tests described by Stacey (2006b) and Aydan et al. (1989) illustrate that, prior to failure, deformations may take place throughout the rock mass. The centrifuge loaded models (Stacey, 2006b) also showed that different locations on the slope face displaced differently at different times prior to the occurrence of a collapse, an example of which is shown in Figure 5. After collapse, it may be observed that much of the rock mass in which deformations were observed remains 'stable' and does not form part of the collapse volume.

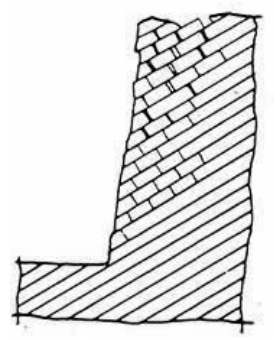

$8 g$

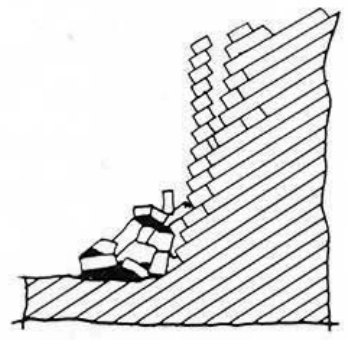

$12 \mathrm{~g}$

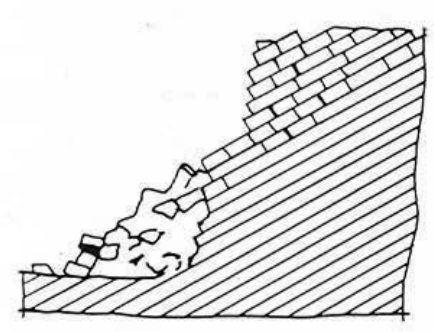

$275 \mathrm{~g}$

Figure 5 Slope with bedding and cross joints (joint spacing to bedding spacing ratio 1.87)

Recent numerical analyses of such models (Salim and Stacey, 2006) show that variability in the geometry of the jointing can have a significant effect on the slope behaviour, and on the geometry and extent of the volume of collapse. Thus, in the same 'statistically defined' rock mass structure, significantly different slope stabilities may result due to the variability.

The relatively recently available slope radar monitoring equipment, which effectively monitors displacements in real time, has demonstrated that the type of behaviour seen in the results from the model tests are also seen in real open pit slopes. Figure 6 shows a sequence of slope displacement results which illustrate that movements monitored at different times have taken place in different locations, i.e. there is an irregular development of displacements across the face. The arrows show the locations of maximum displacement. The apparent concentration at the base of the images is due to mining operations and not slope movements. Note that in this figure there is a change in scale between image 3 and image 4 . The final record also has a substantially different displacement scale and is an accumulation of displacements over a longer period of time. It shows a concentration of displacements near the toe of the slope and another concentration near the crest of the failure that subsequently occurred. It is certainly not apparent that there is any rigid body or homogeneous mass type of movement on a defined shear failure surface that might be representative for a limit equilibrium analysis. 


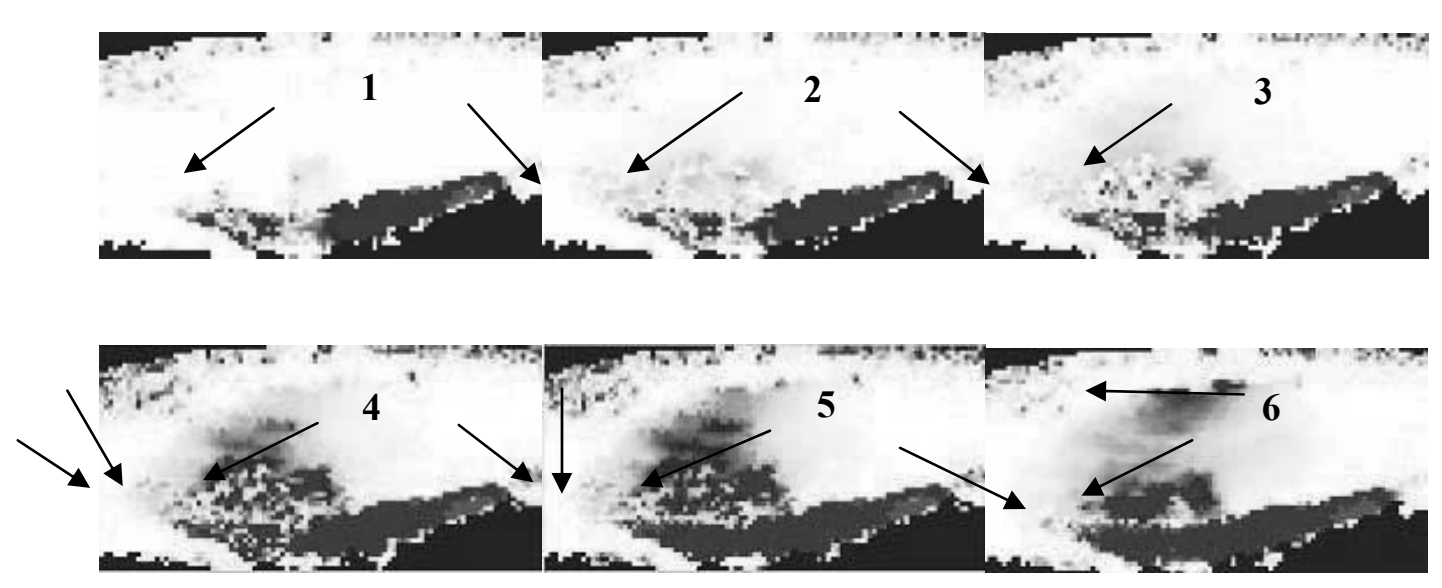

Figure 6 Slope radar sequence showing deformation development

Do major planes of weakness provide surfaces on which large failures move? It is possible, but it is more likely that, on a large scale, such planes are likely to form 'boundaries' to an unstable mass of rock. Such boundaries may facilitate or inhibit movements. A parallel situation is the development of caving in underground mining using caving methods, which effectively represents the development of slopes naturally in a rock mass. As illustrated in Figure 7, the subsidence angle may be steeper or shallower than the angle that would develop in the absence of a plane of weakness. Hence, intersecting major planes in a rock slope may define a wedge, within which the rock mass has greater freedom to deform. The initiation of localised failure and its progression will be facilitated within this zone of greater freedom of movement, allowing the ultimate development of rock slope failure.

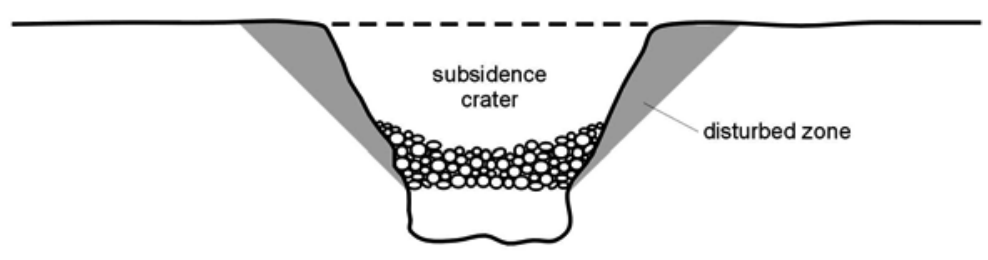

uniform rock mass

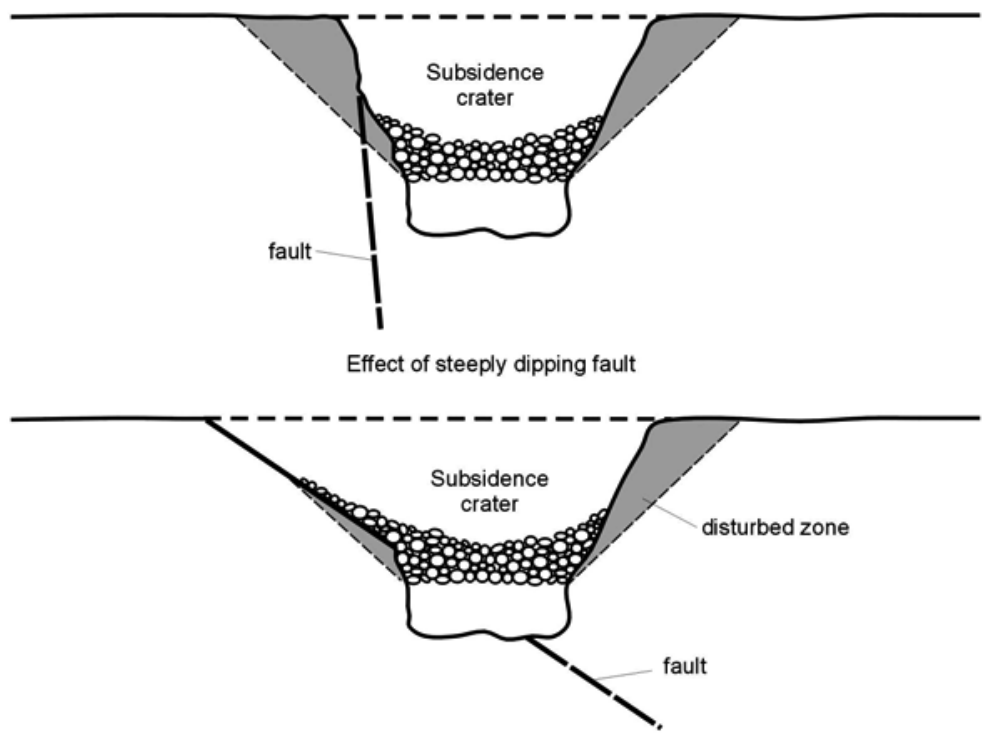

Effect of shallow dipping fault

Figure 7 Beneficial and detrimental effects of major weakness planes (Stacey and Swart, 2001) 
The development of progressive failure in hard rock slopes will involve initiation and progression of failure along existing weakness planes, as illustrated in the model results described above, and initiation and progression of failure of intact rock, as indicated by the failures of the real rock slopes described above. It may be concluded therefore that there will usually be little or no relationship between the volume within which initiation of failure, and deformations, take place, and the volume involved in the ultimate collapse. There may also be no similarity between the mechanisms involved in the initiation and progression of failure, and the mechanisms of ultimate collapse. Thus, whilst initiation and progression may involve a large volume and be deep seated, usually collapse will involve the near surface zone. It is perhaps questionable whether seated collapses can occur since the rock mass is well confined in these deep seated zones. In this regard, it is considered worthwhile quoting from Eberhardt et al. (2004), '.... it can be reasoned that shear along a potential rock slope failure surface only becomes a factor once it's fully developed and mobilization becomes possible. In other words, the failure surface only becomes a 'shear' surface once tensile extensional fracturing has progressed to the point where significant cohesion loss has occurred along the path of coalescing fractures and larger displacements become kinematically feasible ...'

Failure on weakness planes is directional, and dependent on the orientations of the planes. The rock mass will therefore be weaker in some directions than in others. For this reason it is questionable whether a rock mass strength approach, in which an overall rock mass strength criterion is adopted, has validity.

Slope behaviour and slope failures are always three dimensional. However, almost all slope stability analyses and design analyses carried out are two dimensional. The third dimension can have a significant influence on both the stability of the slope and the volume of failure, should failure occur. Neglect of this factor (or simply applying a rule of thumb adjustment) is a serious shortcoming of the current state of the art. Interpretation and extension of results using a joint trace model (Armstrong and Stacey, 2005), and correlation with results from two three dimensional models indicates that the beneficial effect of concave curvature of the slope disappears at a normalised radius of curvature (slope toe radius divided by slope height) of about ten, as shown in Figure 8. Piteau and Jennings (1970), in extrapolating empirical data on slopes associated with the mining of diamond pipes, found that the effect of plan radius of curvature only became negligible for radii in the region of 20 times the slope height. However, their results referred to the slope plan radius at surface, whereas the results in Figure 8 refer to the plan radius at the toe of the slope, so there is probably reasonable agreement between the theoretical and observational results.

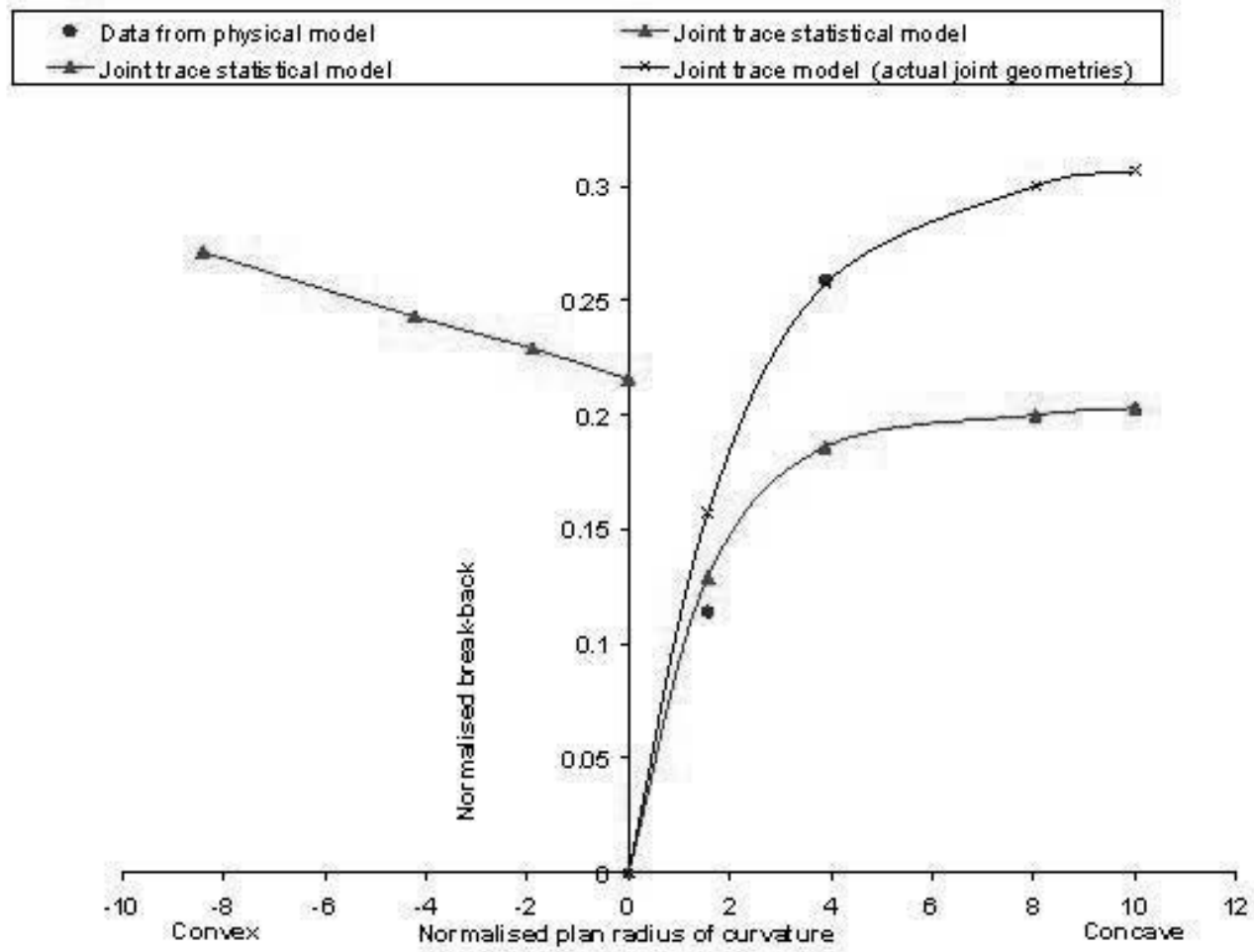

Figure 8 Extent of three dimensional benefit (Armstrong and Stacey, 2005) 
An important aspect of the three dimensional concave slope effect is that it will reduce the volume of failure and depth to which the collapse extends behind the slope face. Evaluation of the stability of this collapse zone, based on before and after observations of the rock slope, but ignoring the three dimensional geometrical effect, may therefore provide parameters of doubtful value for further slope design.

\section{Implications for slope design and stability prediction}

At this stage it is considered appropriate to introduce the requirements for robust design. The design of rock slopes, and the design of slope monitoring systems, should be a thorough process that takes into account adequate information and provides a design with an acceptable risk (Terbrugge et al., 2006). A design methodology corresponding with the design principles developed by Bieniawski (1992) is summarised in the ten steps shown in the wheel of design (Stacey, 2006a) in Figure 9. This methodology represents a thorough design process and can be used as a checklist to ensure that a robust design has been carried out. There is great similarity between this design process and the strategic planning process developed by Ilbury and Sunter (2005), from which it can be implied that design is strategic.

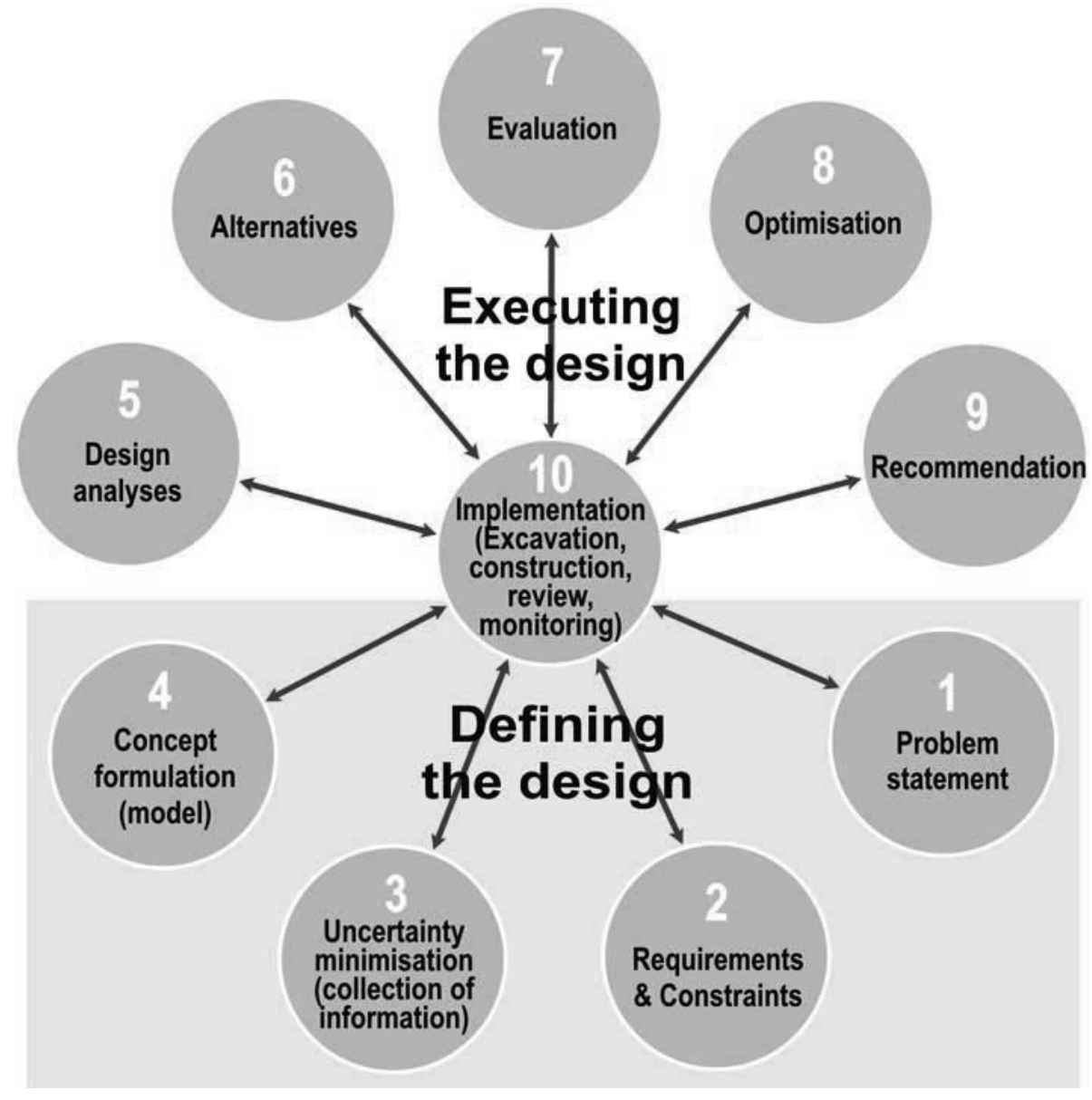

Figure 9 The wheel of design (Cawood and Stacey, 2006)

Some segments of the wheel need to be emphasised. The problem statement (1) ensures that all parties understand what is being designed and the constraints (2) on the design. The 'defining the design' part of the process (1-4) is most important, and the formulation of the geotechnical or conceptual model (4) is critical. The basis for this is a comprehensive site investigation (minimisation of uncertainty), a significant aspect of which should be a thorough structural geological interpretation. This will assist in the identification of major planes of weakness and how these may influence potential slope failure mechanisms, and will also provide information on the characteristics of the rock mass (the rock materials, the joint parameters, etc). If the input information is inadequate, and the geotechnical model (including the interpretation of mechanisms of behaviour and choice of appropriate failure or design criteria) is incorrectly formulated, the answers obtained 
from the stability and design analyses may be wrong. It is the thorough understanding of the expected slope behaviour (where will movements take place, what magnitudes of movements will occur, how rapidly will movements occur? etc.) that allows a satisfactory slope stability evaluation and slope design to be carried out. The stability analysis and the choice of the method of analysis follows from this. With the software available nowadays, sophisticated analyses can be carried out. It is to be noted, however, that these usually require the choice of a rock mass failure criterion. As discussed above, the development of failure in a rock slope will involve multiple modes of failure and will therefore involve multiple failure criteria. The adoption of a single criterion in numerical analyses will dictate how slope failure progresses in the model rather than model how failure would develop naturally. If the criterion is inappropriate, the analysis will also be inappropriate. That is, the sophisticated analysis provided by the readily available numerical code may provide results for the wrong problem.

Monitoring is an important aspect in the design process. One of the main aims of such monitoring should be to check whether the mechanism of behaviour of the designed structure or opening is as expected and whether the design criteria used are appropriate - in other words, to confirm the validity of the design. If the behaviour is not as expected then it will be necessary to loop back to an earlier step in the process and reassess the design. It may even be necessary to carry out a completely new design. The sooner that monitoring information or data can be obtained the better, since costly errors and consequences will then have the best chance of being avoided. The monitoring system should therefore be designed (using the same design process) and implemented before slope excavation commences. The importance of review and monitoring in the engineering design process is emphasised by the 'spokes' of the wheel in Figure 9. They indicate that, at every stage of the design process, the design objectives must be satisfied. The availability of laser, slope radar, satellite radar, GPS, automated prism survey, and seismic monitoring systems means that nowadays slope behaviour can be monitored on a real time basis and the data produced can be fed back into the slope design.

A very common use of observational and monitoring data is in the back analysis of failures or other behaviour. The purposes of this may include the identification of characteristics of behaviour, the establishment of empirical criteria, and the determination of rock mass and failure plane strength parameters. Often such data are used to 'calibrate' the rock mass so as to be able to interpolate and extrapolate the design (Diering and Stacey, 1987). Examples of such a process are that related to the effect of underground block cave mining on the open pit slopes at Palabora Mine described by Brummer et al. (2006), and the explanation of failure by Lucas (2006). The ability to carry out quality back analyses depends very heavily on the availability of good monitoring and observational data, i.e. the development of high quality case study information. The case study approach is promoted very strongly by Hustrulid (2006), to develop a 'bank' of such case studies on a special website. With the monitoring tools available, a 'bank' of case studies should become a very real possibility. However, the success of such an approach will be critically dependent on the willingness of mining companies to make their data freely available. Based on past experience, this is unlikely, particularly if there are safety issues associated with the cases. Information from cases that may have negative influences on the share price is also likely to be suppressed. Further, failures can often be traced back to management decisions (or the lack thereof), and management may therefore understandably be reluctant to release information that would be detrimental to those involved.

Whilst it is important for back analyses to be carried out in an attempt to improve understanding, the use of back analyses for the determination of strength and deformation parameters for design and analysis purposes is considered to be problematic. The description of slope behaviour given in the section above has demonstrated that a slope failure usually will involve deformations and local failures throughout the slope, with the culmination of these smaller failures being the final failure or collapse, perhaps on a 'failure plane', but perhaps not. Often there are multiple mechanisms involved in the local and larger scale failures - shear, tension, extension, crushing, rotation, bending, etc. Failures also involve three dimensions, not two. In such cases, what should be back analysed? Is there any validity in a back analysed shear strength on the perceived 'failure plane'? Is there any validity in back analysed rock mass cohesion, friction and deformability parameters and their use for 'calibration' of the slope or rock mass? It is probable that in many hard rock cases, there is no 'failure plane' until an instant before failure occurs. Brittle failures ultimately result in the collapse. An interesting possibility is that such failure surfaces may initially have very low frictional 
strength. Mechanisms that might promote such 'frictionless' behaviour are the block rotation or hinges proposed by Tarasov and Randolf (2007), and the influence of vibrations in the rock mass.

The use of numerical modelling to explain failures (i.e. a back analysis mode) can form the basis for future design in that environment. However, whilst the explanation may appear credible, it probably will not be the only possible explanation. The success of such approaches in absolute prediction mode is likely to be low. The attempts at prediction of subsidence, described by Kay et al. (1991), illustrate the limited success achieved by several numerical codes in an equivalent environment.

The difference between design and prediction must be emphasised. Design incorporates a desired factor of safety or probability of failure, which caters for uncertainty. This uncertainty will include at least the following: uncertainty in geotechnical properties; uncertainty in boundary conditions; uncertainty in groundwater conditions; uncertainty in the methods of analysis and their validity. The greater the uncertainty, the greater the factor of safety needs to be. The knowledge of the behaviour of the rock slope is therefore 'relative' and is masked by the factor of safety. This is not the case when prediction of slope behaviour is required, which includes the evaluation of stability and prediction of deformations, locations of deformations etc. In this case, knowledge of the behaviour of the slope needs to be 'absolute'.

Notwithstanding what has been written above regarding the requirements for a robust design, satisfactory slope designs may be carried out empirically purely on the basis of experience, or using perhaps inadequate geotechnical slope models and inappropriate methods of analysis with the basis of experience, provided that a suitable factor of safety is used. The use of case study and back analysis data for slope design can be very useful. Empirical observations - 'this slope angle has worked well in the past, therefore it can be used in the future' - are often directly applicable. For example, a method of slope stability analysis may have been used at an open pit since commencement of excavation, and experience of some failures (and back analysis) may have determined a 'suitable' factor of safety for design purposes. The factor of safety satisfactorily compensates for the lack of knowledge. These non-robust, but satisfactory slope design methods cannot be used with confidence beyond the scope of the experience base.

\section{Discussion}

The information above shows that in high stress, hard rock conditions the experience base in slope stability analysis and slope design is of questionable validity. In high stress situations therefore, better understanding of the rock mass and new approaches to analysis will be required for robust design and analysis in the future. But how can better understanding of the rock mass be gained? It has been shown in the section above that small variations in orientations and strengths of planes of weakness may have a significant influence on slope behaviour. The structure of the rock mass is only known explicitly on the exposed rock faces. The strength and deformation parameters of the rock and the planes of weakness in these exposures will never be known explicitly everywhere. Behind the exposed faces information is only available at particular points from borehole exploration, or possibly from underground access, and may be enhanced by geophysical exploration techniques. The boundary conditions, mainly the in situ stresses and the ground water conditions, are also not known explicitly. The rock mass is therefore unknown in an explicit sense. There is variability in all the components making up the rock mass. Therefore, if slope stability analysis is to be valid in the future, all the variability needs to be taken into account by defining statistical distributions for all the parameters involved. This implies that there must be better quality data, and quantity of data, obtained from site investigation work. The new generation of slope monitoring techniques, particularly radar and seismic monitoring, will provide some useful data for such purposes. At this stage, however, there is no published information on detailed interpretations of radar data. This situation is likely to be rectified in the next few years.

A suggested approach to slope stability analysis and slope design for the future is the following, part of which is already in place (e.g. Pine et al., 2006):

- Using the statistical distributions, a theoretical rock mass must be generated. This will define a possible pattern of geological planes of weakness within the rock mass.

- The behaviour of the slope in this rock mass analysed. This will involve analysis of progressive failure development (on planes of weakness and through intact rock) under the imposed stress 
conditions, taking into account multiple possible failure criteria so that failure may develop 'naturally', not as dictated by defined criteria such as Mohr Coulomb or Hoek-Brown. This analysis will also take into account the statistical variations of the strengths and deformabilities of the planes of weakness and the intact rock.

- The analysis must be three dimensional.

- The results of the analysis will provide one possible result regarding the stability of the slope. The process must be repeated many times using different sampled input parameters and alternative theoretical rock masses, with the stability of the slope ultimately evaluated probabilistically.

- The distribution of possible results will provide the basis for a decision on the acceptability of the risk of failure. The risk criterion should be determined by the safety and financial policies of the mine or project executives or owners (Terbrugge et al., 2006).

This is an analysis approach that should be aimed at, but it is not practically achievable at this stage. It might be feasible in two dimensions, and this would provide a significant advance in the understanding of slope behaviour and the validity of stability analyses. As indicated above, part of the approach is already available. Pine et al. (2006) describe a method in which a theoretical rock mass is generated as above. A two dimensional section through this rock mass is then analysed using a hybrid finite and discrete element model in which the weakness planes and intact rock are both modelled. The results obtained from this approach appear to be very realistic. Similar approaches for the generation of theoretical rock masses have been developed by others and have been used successfully for prediction of instability in underground situations (Stacey and Haines, 1984; Butcher, 2000; Grenon and Hadjigeorgiou, 2003; Stacey et al., 2005). The hybrid finite/discrete element method used by Eberhardt et al. (2004) for analysis of the Randa rockslide produced realistic results. This method is exciting in terms of its potential, and is probably the most advanced approach for rock slope stability evaluation currently available.

\section{Conclusions}

Conventional approaches for the evaluation of stability of rock slopes in a high stress, hard rock environment are of questionable validity. This is the environment that is increasingly being experienced in the new generation of very deep open pits being excavated and in the planning stages. The development of progressive failure in hard rock slopes involves initiation and progression of failure along existing weakness planes, and initiation and progression of failure of intact rock. There will usually be little or no relationship between the volume within which initiation of failure, and deformations, take place, and the volume involved in the ultimate collapse. There may also be no similarity between the mechanisms involved in the initiation and progression of failure, and the mechanisms of ultimate collapse. Initiation and progression may involve a large volume of the rock mass and be deep seated, but collapse will usually involve the near surface zone.

What is required for robust stability evaluation and design is much better understanding of the rock mass, and methods of analysis that can model this rock mass and take into account the variability in all of the geotechnical parameters. Better site investigations and modern methods of slope monitoring should supply considerable information regarding the understanding of the rock mass. Owing to geotechnical variability, data from such sources must be expressed in the form of statistical distributions, and methods of stability analysis must therefore necessarily be probabilistic rather than deterministic. The output from such analyses will not be a single evaluation, but a distribution of evaluations that will form the basis for a decision on the acceptability of risk of failure. The methods required for such analyses are already available in theory, but cannot be practically implemented because of lack of computing power. In particular, the requirement for analyses to be probabilistic and three dimensional places enormous demands on computing capacity. The resolution of this problem will simply be a matter of time.

\section{References}

Armstrong, R. and Stacey, T.R. (2005) The extent and volume of three dimensional failures in rock slopes in which several sets of joints define the geological structure. Proc. 3rd Southern African Rock Engineering Symp. Best practices in rock engineering, Randburg, S. Afr. Inst. Min. Metall., Symposium Series S41, pp. 201-209. 
Aydan, Ö., Shimizu, Y. and Ichikawa, Y. (1989) The effective failure modes and stability of slopes in rock mass with two discontinuity sets. Journal Rock Mechanics and Rock Engineering, Vol. 22, No. 3, Springer Verlag Vienna, July 1989, pp. 163-188.

Bieniawski, Z.T. (1992) Invited Paper: Principles of engineering design for rock mechanics, Rock Mechanics. Proc. 33rd US Symp. on Rock Mech., Ed. Tillerson \& Wawersik, Balkema, pp. 1031-1040.

Brummer, R.K., Li, H. and Moss, A.S.E. (2006) The transition from open pit to underground mining: an unusual slope failure mechanism at Palabora. Proc. Int. Symp. on Stability of Rock Slopes in Open Pit Mining and Civil Engineering, S. Afr. Inst. Min. Metall.

Butcher, R.J. (2000) A modelling method for predicting block cave cavability, initial fragmentation and production tonnage at a scoping study level. MScEng Research Report, University of the Witwatersrand.

Cawood, F.T. and Stacey, T.R. (2006) Survey and geotechnical slope monitoring considerations, Jl S. Afr. Inst. Min. Metall., Vol. 106, No. 7, pp. 495-501.

Diering, J.A.C. and Stacey, T.R. (1987) Three-dimensional stress analysis: a practical tool for mining problems, APCOM 87. Proc. 20th International Symposium on Application of Computers and Mathematics in the Mineral Industries, Vol. 1, Mining, Johannesburg, 1987, S. Afr. Inst. Min. Metall., pp. 33-42.

Dight, P.M. (2006) Pit wall failures on “unknown” structures. J1 S. Afr. Inst. Min. Metall., Vol. 106, pp. 451-458.

Eberhardt, E., Spillmann, T., Maurer, H., Willenberg, H., Loew, S. and Stead, D. (2004) The Randa Rockslide Laboratory: establishing brittle and ductile instability mechanisms using numerical modelling and microseismicity. Landslides: Evaluation and Stabilization, Lacerda, Ehrlich, Fontoura and Sayao (eds), Taylor \& Francis Group, London, pp. 481-487.

Grenon, M. and Hadjigeorgiou, J. (2003) Open stope stability using 3D joint networks. Rock Mech. Rock Engineering, Vol. 36, No. 3, pp. 183-208.

Hoek, E., Rippere, K.H. and Stacey, P.F. (2000a) Large-scale slope designs - a review of the state of the art. In Slope Stability in Surface Mining, Hustrulid, McCarter \& Van Zyl (eds), SME, Colorado, pp. 3-10.

Hoek, E., Read, J., Karzulovic, A. and Chen, Z.Y. (2000b) Rock slopes in civil and mining engineering. Proc. GEOENG 2000, Invited paper, $16 \mathrm{p}$.

Hustrulid, W. (2006) Some thoughts regarding mining and rock mechanics. Newsletter Volume 27, Australian Centre for Geomechanics, December, pp. 1-3.

Ilbury, C. and Sunter, C. (2005) Games foxes play - planning for extraordinary times. Human \& Rosseau Tafelberg, $180 \mathrm{p}$.

Kay, D.R., McNabb, K.E. and Carter, J.P. (1991) Numerical modelling of mine subsidence at Angus Place Colliery. Proc. Symp. Computer Methods and Advances in Geomechanics, de Beer, Booker and Carter (eds), Balkema, pp. 999-1004.

Lucas, D. (2006) Stress failure of a shallow open cut mine. Newsletter Volume 27, Australian Centre for Geomechanics, December, pp. 4-6.

Lynch, R.A., Wuite, R., Smith, B.S. and Cichowitz, A. (2005) Microseismic monitoring of open pit mines. Proceedings RaSIM6 - Controlling the Seismic Risk, pp. 259-266.

Mercer, K.G. (2006) Investigation into the time dependent deformation behaviour and failure mechanisms of unsupported rock slopes based on the interpretation of observed deformation behaviour. PhD Thesis, University of the Witwatersrand.

Merrill, R.H. and Wisecarver, D.W. (1967) The stresses in rock around surface openings. In Failure and Breakage of Rock, C. Fairhurst (editor), AIME, New York, pp. 337-350.

Moss, A., Diachenko, S. and Townshend, P. (2006) Interaction between the block cave and the pit slopes at Palabora Mine. Jl S. Afr. Inst. Min. Metall., Vol. 106, pp. 479-484.

Naismith, W.A. and Wessels, S.D.N. (2005) Management of a major slope failure at Nchanga Open Pit, Chingola, Zambia. J1 S. Afr. Inst. Min. Metall., Vol. 105, pp. 619-626.

Pine, R.J., Coggan, J.S., Flynn, Z.N. and Elmo, D. (2006) The development of a new numerical modelling approach for naturally fractured rock masses. Rock Mech. and Rock Engineering, Vol. 39, No. 5, pp. 395-419.

Piteau, D.R. and Jennings, J.E. (1970) The effects of plan geometry on the stability of natural slopes in rock in the Kimberley area of South Africa. Proc. 2nd Int. Cong. Int. Soc. Rock Mech., Belgrade, Vol. 3, Theme 7, Paper No. 4.

Salim, A. and Stacey, T.R. (2006) Unstable rock slope behaviour in discontinuous rock masses. Proc. Symp. Facing the Challenges, S. Afr. National Institute of Rock Engineering, Rustenburg, pp. 30-45.

Simmons, J.V. and Simpson, P.J. (2006) Composite failure mechanisms in coal measures' rock masses - myths and reality. Jl. S. Afr. Inst. Min. Metall., Vol. 106, pp. 459-469.

Sjoberg, J. (2000) Failure mechanisms for high slopes in hard rock. In Slope Stability in Surface Mining, Hustrulid, McCarter and Van Zyl (eds), SME, Colorado, pp. 71-80.

Stacey, T.R. (2006a) Design - a Strategic Issue. Proc. 2nd Int. Seminar on Strategic vs Tactical Approaches in Mining, Perth, Australian Centre for Geomechanics, Section 4, 13 p. 
Stacey, T.R. (2006b) Considerations of failure mechanisms associated with rock slope instability and consequences for stability analysis. Jl. S. Afr. Inst. Min. Metall., Vol. 106, pp. 485-493.

Stacey, T.R., Wesseloo, J. and Bell, G. (2005) Predicting the stability of rockpasses from the geological structure. Jl. S. Afr. Inst. Min. Metall., Vol. 105, No. 11, pp. 803-808.

Stacey, T.R., Wesseloo, J. and Lynch, R. (2004) "Extension" and seismicity in a hard rock open pit mine. Proc. 2nd Int. Seminar on Deep and High Stress Mining, S. Afr. Inst. Min. Metall., pp. 41-53.

Stacey, T.R., Terbrugge, P.J., Keyter, G.J. and Yu, Xianbin (2003a) Extension strain - a new concept in open pit slope stability, and its use in the explanation of two slope failures. Proc. 5th Large Open Pit Conf., Kalgoorlie, Aus.I.M.M., pp. 259-266.

Stacey, T.R., Xianbin, Y., Armstrong, R. and Keyter, G.J. (2003b) New slope stability considerations for deep open pit mines. Jl S. Afr. Inst. Min. Metall., Vol 103, No. 6, pp. 373-389.

Stacey, T.R. and Swart, A.H. (2001) Practical Rock Engineering Practice for Shallow and Opencast Mines. SIMRAC, The Safety in Mines Research Advisory Committee, 66 p.

Stacey, T.R. (1996) Stress analysis and three dimensions in rock slope stability. In Milestones in Rock Engineering, A.A. Balkema, pp. 173-187.

Stacey, T.R. and Haines, A. (1984) Design of large underground openings in rock - an integrated approach. Proc. Seminar on Design and Construction of Large Underground Openings, S. Afr. Nat. Committee on Tunnelling, November 1984, pp. 17-25.

Sweby, G. (2004) WA research examines microseismic emission in open pit mining. Newsletter Volume 22, Australian Centre for Geomechanics, August, pp. 12-13.

Tarasov, B.G. and Randolph, M.F. (2007) Frictionless shear at great depth and other paradoxes of hard rocks. Int. J. Rock Mech. Min. Sci, submitted for publication.

Terbrugge, P.J., Wesseloo, J., Venter, J. and Steffen, O.K.H. (2006) A risk consequence approach to open pit slope design. Jl. S. Afr. Inst. Min. Metall., Vol. 106, pp. 503-511.

Wyllie, D.C. and Mah, C.W. (2004) Rock slope engineering: civil and mining, Spon. Press. 